\title{
Influencing Factors of Melasma
}

\author{
Dhara Alifa \\ Faculty of Medicine, Maranatha Christian University, \\ Bandung,Indonesia \\ R. Amir Hamzah \\ Dermatology and Venerology Department, Faculty of Medicine,Maranatha Christian University \\ Bandung,Indonesia \\ Jeanny E. Ladi \\ Histology Department, Faculty of Medicine, Maranatha Christian University \\ Bandung,Indonesia \\ Correspondent email:dharaalifa95@gmail.com \\ DOI: $10.31364 / \mathrm{SCIRJ} / \mathrm{v} 9.110 .2021 . P 1021884$ \\ http://dx.doi.org/10.31364/SCIRJ/v9.i10.2021.P1021884
}

\begin{abstract}
Background: Melasma is a disorder characterized by hyperpigmented macular lesions on the frequently sun-exposed skin. Melasma often occurs and becomes a cosmetics problem that lowers confidence. The cause of melasma is not yet known. Objective: Purpose of this research is analyzing factors associated to melasma in order to improve knowledge and the understanding of the factors that influence the occurrence of melasma. Method: Design of this study was descriptive observational study with cross sectional study. Data for this study was obtained from questionnaires and interviews. The sample size used was whole sampling. Results: The most attained results in each factors was age, Female $(99,10 \%)$, family history $(64,86 \%), 31-40$ years $(47,75 \%)$, Housewife $(44,14 \%)$, sunlight $2-3$ hours $(42,34 \%)$, history of hormonal contraceptive $(31,81 \%)$, history melasma in pregnancy $(27,88 \%)$, hormonal disease $(12,73 \%)$. Conclusion: Incidence of melasma has a multifactorial effect but factors gender and family history or genetics maybe strong influencing to the majority of patients.
\end{abstract}

Keywords : Melasma, Influencing Factors, Female, genetics

\section{INTRODUCTION}

Melasma is a disorder characterized by hyperpigmentation macular lesions on the skin that are often exposed to sunlight such as the face, neck, or arms. Melasma is still common in society as a cosmetic problem that can decrease confidence for both female or male, but melasma is very rare in male.[1]

Melasma is a multifactor disorder whose main cause is not yet known for certain, but melasma can be associated with several factors such as age, gender, hormones, sun exposure, contraceptive methods, thyroid function, pregnancy, genetics, medications, occupation, phototoxic, photoalergics, and other disease histories. Melasma can occur during pregnancy, it is possible that melasma can disappear within a few months spontaneously. Estrogen and progesterone hormone therapy for the prevention of osteoporosis can be one of the influence factors of melasma. Adrenokortisol hormones and sex hormones can activate melanocyte cells that are the cause of melasma. These factors are thought to cause abnormalities in melanocytes and increase melanogenesis.[1]

\section{II.METHOD}

The tools and materials used in this study are questionnaires and interviews. The population of the study subjects were patients with melasma who came to Dermatology clinic of Al-Islam Hospital Bandung, West java, Indonesia in October 2016, and were willing to fill out questionnaires. The number of samples taken is whole sampling. Respondents who were willing, asked to fill out questionnaires or answer interview questions about age, gender, occupation, melasma history, history of sun exposure, history of contraceptive use, pregnancy history, history of disease first, and family history of disease. The design of this study is observational analytical research using cross sectional research design. The variables of this study are age, gender, occupation, history of sun exposure, history of contraceptive use, history of pregnancy, history of disease first, and family history of disease.

\section{III.RESULTS}

In this study, the prevalence of melasma was most common in the $31-40$ age group (47.8\%), with the majority being female $(99.1 \%)$ and the most jobs were housewife $(44.1 \%)$.

Table 1: Characteristics

\begin{tabular}{ccccc}
\hline No & $\begin{array}{c}\text { Characteristi } \\
\text { cs }\end{array}$ & Categories & $\begin{array}{c}\mathbf{N} \\
(\mathbf{1 1 1})\end{array}$ & $\mathbf{\%}$ \\
\hline 1 & Age (years) & $<21$ & 6 & 5.4 \\
& & $21-30$ & 20 & 18.0 \\
& & $31-40$ & 53 & 47.8 \\
& & $41-50$ & 27 & 24.3 \\
& & $51-60$ & 5 & 4.5 \\
2 & \multirow{4}{*}{ Gender } & Female & 110 & 99.1 \\
& & Male & 1 & 0.9 \\
& & & & \\
3 & \multirow{3}{*}{ Occupation } & Housewife & 49 & 44.1 \\
& & Employees & 29 & 26.2 \\
& & State Officials & 15 & 13.5 \\
& & Others & 18 & 16.2 \\
\hline
\end{tabular}

The results of this study obtained the most number in the group of people who were exposed to the sun for about 2-3 hours per day with a percentage of $42.3 \%$.In patients with 
melasma women obtained $31.8 \%$, a disease arises during the use of hormonal contraceptives. While melasma arises in $27.9 \%$ when pregnant in those who have a pregnancy history as many as 104 people. While patients who have a history of hormonal diseases, such as ovarian tumors, uterine myomas, ovarian cysts, thyroid abnormalities, and breast tumors, as many as $12.7 \%$ of female melasma sufferers.

Table 2: Associated Factors

\begin{tabular}{|c|c|c|c|c|}
\hline No & Characteristics & Cathegories & $\mathbf{N}$ & $\%$ \\
\hline \multirow[t]{4}{*}{1} & Sun Exposure & $<1$ & 37 & 33.3 \\
\hline & (hours) & $2-3$ & 47 & 42.3 \\
\hline & & $>5$ & 27 & 24.4 \\
\hline & Total & & 111 & 100 \\
\hline \multirow[t]{3}{*}{2} & Contraception & Use & 35 & 31.8 \\
\hline & (Female) & Not Use & 75 & 68.2 \\
\hline & Total & & 110 & 100 \\
\hline \multirow[t]{3}{*}{3} & Melasma History & Yes & 29 & 27.9 \\
\hline & in pregnancy & No & 75 & 72.1 \\
\hline & Total & & 104 & 100 \\
\hline \multirow[t]{3}{*}{4} & Family history of & Yes & 72 & 64.9 \\
\hline & illness & No & 39 & 35.1 \\
\hline & Total & & 111 & 100 \\
\hline \multirow[t]{4}{*}{5} & History of & Yes & 14 & 12.7 \\
\hline & Hormone & No & 96 & 87.3 \\
\hline & correlated illnes & & & \\
\hline & Total & & 110 & \\
\hline
\end{tabular}

The number of factors that play a role in the occurrence of melasma in each of the subjects, $46.7 \%$ have 2 or more associated factors related to melasma.

Table 3: Number of factors associated

\begin{tabular}{ccc}
\hline Factors Number & $(\mathbf{N})$ & Percentage \\
\hline 0 & 9 & $8.1 \%$ \\
1 & 50 & $45.2 \%$ \\
2 & 34 & $30.6 \%$ \\
3 & 17 & $15.3 \%$ \\
4 & 1 & $0.9 \%$ \\
Total & 111 & $100 \%$ \\
\hline
\end{tabular}

\section{Discussion}

The average age of melasma sufferers in this study (table 1) was categories 31-40 years old (mean 37 Years old). Research in India, Singapore, and the world shows the average age of melasma was 30, 34, and 38 years old. Other studies conducted in Mexico show as many as $70 \%$ of melasma sufferers were people aged from 30-40 years old. The results of this study were similar to previous studies that showed the most frequent incidence of melasma occurred at the age of 31-44 years old. It is likely that there are high levels of the hormones estrogen and progesterone in the group of 30-40 years old. Melasma is rare in people who have not yet puberty and usually appears when the age is reproductive. The influence of changes in the hormones estrogen and progesterone, intensity of sun exposure, and increased synthesis of melanin may affect the occurrence of melasma in this age group. Melasma is rare in people aged 50 and over due to the possibility of menopause, decreased estrogen hormones, and decreased melanocyte count and activity, especially in parts that are rarely exposed to the sun.[2]

The results of studies in Brazil and Singapore showed that women experienced more melasma with a ratio of 39:1 and 21:1. Research conducted at the Faculty of Medicine, University of Indonesia / Hospital Dr.Cipto Mangunkusumo in 2004 received a percentage of female sufferers as much as $97.93 \%$ and male melasma sufferers by $2.07 \%$ similar with this study (table 1). These results show melasma was more common in women. The influence of female sexual hormones, such as estrogen and progesterone, can affect the onset of melasma, another factors that usually causes melasma in women are pregnancy, sun exposure, and hormonal contraceptives. Male melasma sufferers are usually caused by sun exposure and a history of melasma family diseases. Another factor that allows men to be exposed to melasma less often is the possibility that men usually do not attach importance to cosmetic problems and rarely treat because of melasma.[2,3]

Ultraviolet can stimulate melanocyte cell membranes to produce ROS (Reactive Oxygen Species) which will activate phospholipase (PLC) resulting in diacetyl glycerol (DAG) and free inositoltriphosphat. This activates melanin synthesis. Work and activity factors affect the length of sun exposure. Factors of residential areas can also influence the onset of melasma, people living in the tropics are usually more susceptible to the onset of melasma because the tropics get more and more frequent UV light from the subtropical area. People in mountainous areas are also more often exposed to melasma because mountainous areas are higher and closer to the sun. The use of sun protection, such as sunscreen, hats, masks, helmets, umbrellas, and others, can reduce sun exposure. In this study $66 \%$ were exposed to sunlight for more than 2 hours as shown in table 2. [3,4]

Melasma can occur in women who use hormonal contraceptives as much as $8-34 \%$. In this study contraceptives were used by $27.9 \%$ of melasma sufferers. Hormonal contraceptives such as contraceptive pills, injectable contraceptives, and implants can trigger increased melanogenesis because they contain the hormones estrogen and progesterone causing the possibility of melasma. The hormones estrogen and progesterone can stimulate MSH which plays a direct role against melanocytes and causes an increase in the amount of melanin in cells, while the hormone progesterone causes an increased spread of melanin in keratinocyte cells. Both of these mechanisms are aided by the hormones peptide and glycoprotein and involve the activity of cyclic adenosine monophosphat (c-AMP) on cell membranes. Melasma arising from hormonal contraceptives is usually sedentary.[2,3]

The prevalence of melasma due to pregnancy varies greatly in each region depending on race and other factors. Research conducted in India got a percentage of sufferers $45.30 \%$. Research in southern Brazil found that $10.70 \%$ of melasma sufferers out of 224 pregnant women, and research conducted in Iran, Morocco, and Pakistan found that the percentage of pregnant women with melasma was $16 \%, 37 \%$, and $46 \%$. Melasma that appears during pregnancy occurs in 26$51 \%$ of pregnant women. Table 2 shows the number of melasma sufferers during pregnancy amount of 27.9\%.[5,6,7]

Estrogen and progesterone during pregnancy increase Melanocyte Stimulating Hormone (MSH), as in the use of hormonal contraceptives, which can trigger the process of 
melanogenesis by stimulating the production of tyrosinease and TRP-2 leads to the formation of melasma lesions. Pregnancy in the third trimester, usually melasma begins to arise and expands due to increased levels of hormones produced by the ovaries, pituitary, and placenta. These hormones can stimulate melanogenesis as well. Women with melasma that appear during pregnancy, will usually reappear during the use of hormonal contraceptives.[5,6,8] Hormonal diseases, such as ovarian tumors, uterine myoma, ovarian cysts, and breast tumors, can be caused by an imbalance of sex hormones, estrogen and or progesterone, in the body that allows melasma. $[9,10]$

The results of this study found that there were 72 patients with a family history of melasma (64.86\%). Melasma is related to the SLC24A5 gene which plays a role in determining the number and activity of melanocytes. Abnormalities in this gene can cause disruption in the melanogenesis process and lead to the possibility of developing melasma. Genetic factors are found in $20-70 \%$ of cases of melasma and can increase the likelihood of developing melasma in a person. $[2,3,4]$

Factors of age, gender, occupation, sun exposure, hormonal contraception, pregnancy, hormonal contraception, and genetics. The factors found in one patient are summed and give the results as shown in Table 3 . These results indicate that the causes of melasma can be multifactorial or idiopathic. This depends on each patient. The number of patients two or more influencing factors as many as $46.7 \%$ of patients.

\section{Conclusion}

The incidence of melasma has a multifactorial effect but factors gender and family history or genetics maybe strong influencing to the majority of patients.

\section{Conflict of interest}

The authors declare that they have no conflict of interest regarding the publication of this article.

\section{References}

[1] Bandyopadhyay, D.Topical Treatment of Melasma. Indian Journal of Dermatology. 2009;54(4), pp. 303-309. DOI: 10.4103/0019-5154.57602

[2] Sarkar R, Ailawadi P, Garg S. Melasma in Men: A Review of Clinical, Etiological, and Management Issues. J Clin Aesthet Dermatol. 2018;11(2):53-59.

[3] Handel AC, Miot LD, Miot HA. Melasma: a clinical and epidemiological review. An Bras Dermatol. 2014;89(5):771-782. doi:10.1590/abd1806-4841.20143063

[4] Passeron T.Melasma pathogenesis and influencing factors an overview of the latest research. JEADV 2013, 27 (Suppl.1), 5-6. https://doi.org/10.1111/jdv.12049

[5] Marc T, Gray G. Common skin conditions during pregnancy.Am fam physician 2007;75:211-18

[6] Muller I and Rees.Melasma and Endocrine Disorders. Pigmentary Disorders S1:001. doi: 10.4172/23760427.S1-001

[7] Handel AC, Miot LD, Miot HA. Melasma: a clinical and epidemiological review. An Bras Dermatol. 2014;89(5):771-782.

DOI:10.1590/abd1806-4841.20143063

[8] Lee AY.An updated review of melasma pathogenesis. Dermatologica Sinica.2014;32(4):233-239. doi.org/10.1016/j.dsi.2014.09.006.

[9] Rajanala S, Maymone MBC, Vashi NA. Melasma pathogenesis: a review of the latest research, pathological findings, and investigational therapies. Dermatol Online J. 2019 Oct 15;25(10):13030/qt47b7r28c. PMID: 31735001.

[10] Karjane NW. Ovarian Cyst. [Online] Available.at:http://emedicine.medscape.com/article/25 5865-overview [Accessed 2016 November 2016]. 